\title{
INVESTIGATIONS INTO THE TRANSFORMER INRUSH CURRENT PROBLEM
}

\author{
A. 0. Ekwue ${ }^{1, *}$ and B. Rawn ${ }^{2}$ \\ 1,JACOBS, SiMPSON HOUSE, 6 CHERRY ORCHARD ROAD, CROYDON CR9 6BE, UNITED KINGDOM \\ 2, BRUNEL UNIVERSITY, MIDDLESEX UB8 3PH, UNITED KINGDOM \\ E-mail addresses: ${ }^{1}$ arthur.ekwue@jacobs.com, ${ }^{2}$ barry.rawn@brunel.ac.uk
}

\begin{abstract}
A transformer being energised may draw a large transient current from the grid supply, resulting in a temporary voltage dip at the point of connection (POC) where customers are connected. The voltage dip is dependent upon the magnitude of the transformer inrush current. The peak current of the first cycle, under worst conditions, is considered important. This paper presents the results achieved following the energisation of a $10 M V A 132 / 11 \mathrm{kV}$ transformer as well as the practical mitigation measures to minimise the impact of the transformer energisation.
\end{abstract}

Keywords: transformer saturation; transformer inrush current modelling; voltage drop; PSCAD software.

\section{INTRODUCTION}

When a transformer is energised, it may draw a large transient current from the grid supply, resulting in a temporary voltage dip at the point of connection (POC) where customers are connected. The voltage dip is dependent upon the magnitude of the transformer inrush current which in turn depends on:

- transformer design (i.e. its construction and materials);

- residual flux in the transformer, which may be as much as $50 \%$ to $90 \%$ of the maximum operating flux. This is the amount of flux remaining in the core due to the properties of the magnetic core material.

- network short-circuit level. The short circuit level at any node in a power system is basically a measure of the strength of the AC (Alternating Current) system at that point and

- point on the source-voltage wave that the transformer is energised (i.e. switching angle).

In the UK, for example, the Distribution Code states that for normal routine operations of energising transformers, the voltage step change limits are defined by Energy Networks Association's Engineering Recommendation P28 (ER P28). This covers planning limits for voltage fluctuations caused by industrial, commercial and domestic equipment [1]. This defines a general limit of $3 \%$ on the allowable magnitude of rms voltage drop for switching events occurring in a period exceeding $30 \mathrm{~ms}$ from starting for switching events which occur at least 700 seconds apart.

The absolute value of the residual flux, which remains in the ferromagnetic core, can be quite different from one transformer to another. Its true nature has not been experimentally clarified because the flux values in the transformer core cannot be measured directly and field tests cannot be easily conducted $[2,3]$. It is generally believed that the residual flux, following deenergising of the transformer, will decay slowly over time in a matter of minutes or hours [4] depending on the temperature; at normal temperature we should expect a slower process but it can also remain for a long time. It may be difficult to ascertain the rate of the decay but it is likely that a measureable change may be seen in minutes. The use of hot-rolled steel instead of cold-rolled steel has been suggested for transformer ferromagnetic core. Normally the rate of decay is not seen as an issue as devices can be used, in many cases, to force a decay.

The inrush current can have an effect on the operation of protection relays located in the system near to the transformer. Depending on the transformer design, the magnitude of this current inrush could be from 4 to 40 times the rated full load current. An accurate estimate of the inrush current requires detailed information regarding the transformer design, which may be available from the manufacturer but is not usually available to the application engineers. 
Transformer inrush studies are also of importance in remote rural areas, such as within the Nigerian $33 \mathrm{kV}$ and $11 \mathrm{kV}$ distribution networks, where the power system is weak and energising a large transformer at the wrong time can cause significant voltage dip on the network. Some of their transformers are old and dilapidated with serious financial implications when things go wrong. For example, it was reported during May 2018 in the public press that a 66MVA 132/33kV transformer (and its associated equipment) at the Alagbon transmission substation in Dolphin Estate, Ikoyi, Lagos that was gutted by fire will cost about two million US dollars to replace. In many utilities, the principal hazard associated with this issue is with quality of supply, arising from the inability to supply the demands as required. If this hazard is not addressed, this may result, in some regimes, in fines and compensation payouts which will have an impact on the company's finances, operations, and regulatory integrity.

Transformer inrush currents that may occur on a power system can be categorised as energisation inrush current, recovery inrush or sympathetic inrush. The recovery inrush is said to occur when the transformer voltage is restored after having been reduced by a system disturbance whereas sympathetic inrush current occurs when an un-energised transformer is switched on and the transformers that are already in operation go into saturation [5]. The quantification of the effect of inrush current on voltage dips during transformer energisation as well as the assessment of the probability distributions of voltage magnitudes and durations were reported by Peng in [6]. As only one transformer is involved in the investigations reported in this paper, sympathetic inrush currents are not of prime interest.

Transformer inrush currents are usually determined by considering the peak current of the first cycle under worst case conditions. Yacamini and Abu-Nasser in [7] explored the decay of the inrush current and its DC (Direct Current) component as this may cause disturbances in some telecommunications. Their investigations were extended in [8] to three-phase transformers with varying electrical and magnetic characteristics. Using these methods, it was possible to investigate problems caused by inrush currents in relaying, overvoltage induced HVDC (High Voltage Direct Current) schemes as well as drives with filters or capacitors used for power factor corrections. Further information on the subject of Transformer Inrush Current may be found in [9].
This paper presents a case study involving transformer energisation: $1 \mathrm{MVA} 11 \mathrm{kV} 50 \mathrm{~Hz}$ power supply provided from Distribution Network Operator (DNO) with a fault level of 50MVA is used to energise an unloaded 10MVA $132 / 11 \mathrm{kV}$ delta-to-star connected transformer. The next Section discusses the development of the PSCAD software model whereas Section 3 presents the initial results of this Study. The aim is to provide the basic inrush characteristics and system response in terms of voltage dips. Section 4 investigates mitigation measures to minimise the impact of transformer energisation whereas Section 5 concludes the paper.

\section{PSCAD MODEL and ASSUMPTIONS}

Power system software studies are carried out by developing a detailed electromagnetic model using either PSCAD or EMTP-ATP software packages as they allow a full electromagnetic transient analysis; the PSCAD software is used in this paper. There are other power system software such as PSS/E, ETAP, CYME and IPSA but, as far as the authors are aware of, these do not have electromagnetic transient analysis modelling capability so were not considered. The components used in the development of the PSCAD model are discussed below.

\section{$2.111 \mathrm{kV}$ Network Source Impedance}

A representation of the $11 \mathrm{kV}$ DNO was modelled as an impedance behind a voltage source; the minimum fault level at the $11 \mathrm{kV}$ point of connection (POC) was stated as 50MVA and this will result in the worst voltage dip. The equivalent $11 \mathrm{kV}$ source impedance $=(11)^{2} / 50=$ $2.42 \Omega$ and assuming $X / R$ at the $P O C=0.50$ results in $R$ $=2.16 \Omega$ and $X=1.082 \Omega$ (i.e. $L=0.00345 \mathrm{H}$ ).

The input parameters to PSCAD software using the RLC series configuration are $\mathrm{R}=2.16 \Omega$; $\mathrm{L}=0.00345 \mathrm{H}$ and $\mathrm{C}=0$.

\subsection{Transformer Saturation Characteristics and Impedance}

One of the key steps in the creation of a transformer model for inrush current evaluation is the construction of saturation curve to represent the non-linear behaviour of the core. The three-phase Unified Magnetic Equivalent Circuit (UMEC) Transformer model described in PSCAD was utilised in this Study rather than the simplified General Transformer Model which only represents saturation as a current source placed across a selected winding. Chiesa et al [10] stated that the UMEC transformer model can estimate the first peak of the inrush current with good accuracy 
provided an extensive no-load test report (with maximum induction level of $115 \%$ ) was available.

A technique for the computation of magnetisation and loss curves for a transformer from a standard no-load test report data, assuming that the open-circuit test voltage is sinusoidal, was reported in [11]. This assumption becomes questionable when a relatively low power generator is used to perform the opencircuit test of large transformer units. How to achieve the extrapolation of the curve beyond the last measured point of the open-circuit test remains uncertain though the use of a linear extrapolation and curve fitting techniques have been suggested. This work was extended in [12] by developing a model based on transformer topology to address extreme saturation and inrush current situations. The model was able to determine residual flux correctly and this was validated via measurements. Parameter estimation and sensitivity studies were used to identify the most critical parameters.

The non-linear magnetic saturation characteristics for the 10MVA $132 / 11 \mathrm{kV}$ transformer based on the noload (open-circuit) test report is used to define straight line segments by ten pairs of entered points, as required by the PSCAD software.

The reactance of the 10MVA $132 \mathrm{kV} / 11 \mathrm{kV}$ supply transformer used in the PSCAD model is 8.75\%. The noload loss is 0.00065 per unit whereas the copper loss is 0.00355 per unit. The per-unit no-load and copper losses were specified for the base of the transformer; these parameters were provided by the transformer manufacturer in the data supplied. It is important to note that with the UMEC transformer model, copper loss must also be introduced in order to obtain correct results.

\subsection{Cable Impedance}

The distance between the metering circuit breaker and the $132 \mathrm{kV} / 11 \mathrm{kV}$ supply transformer is measured to be 100 metres. According to the Aluminium $185 \mathrm{~mm}^{2} 11 \mathrm{kV}$ cable data from DNO, the $\mathrm{R}=0.195 \Omega / \mathrm{km}$ and $\mathrm{X}=$ $0.080 \Omega / \mathrm{km}$. Therefore, for a length of 100 metres, the input parameters to PSCAD software are $\mathrm{R}=0.0195 \Omega$ and $X=0.008 \Omega$ (i.e. $L=3.0 \times 10^{-5} \mathrm{H}$ ).

\subsection{PSCAD Network Model}

From the foregoing Sections, the PSCAD model used to carry out the transformer energisation study is shown in Figure 1.

The peak inrush current depends on the instant that the circuit breaker is closed. This is due to the fact that the transformer windings will be subject to different energisation voltages depending on the phasing of the $50 \mathrm{~Hz}$ voltage waveform. In order to determine the highest value of the inrush current, the authors repeated the simulations with the circuit breaker closing at different times by point-on-wave study for transformer energisation.

This is achieved by using PSCAD's multiple-runcomponent to control the closing time of the circuit breaker (BRK1) from one run to another. The multiplerun-component changes the energisation time (EngTime) of the 10MVA $132 / 11 \mathrm{kV}$ transformer. In this way it can be discovered on which point-on-wave (when breaker closes) the maximum inrush current occurs.

The 10MVA $132 / 11 \mathrm{kV}$ transformer is energised by closing the circuit breaker BRK1 at $\mathrm{t}=1 \mathrm{sec}$. The settings for the multiple-run component change the closing time of the BRK1 between 1sec and 1.02sec (i.e. $20 \mathrm{msec}$ across the full $50 \mathrm{~Hz}$ waveform cycle) with increment steps of $2 \mathrm{msec}$.
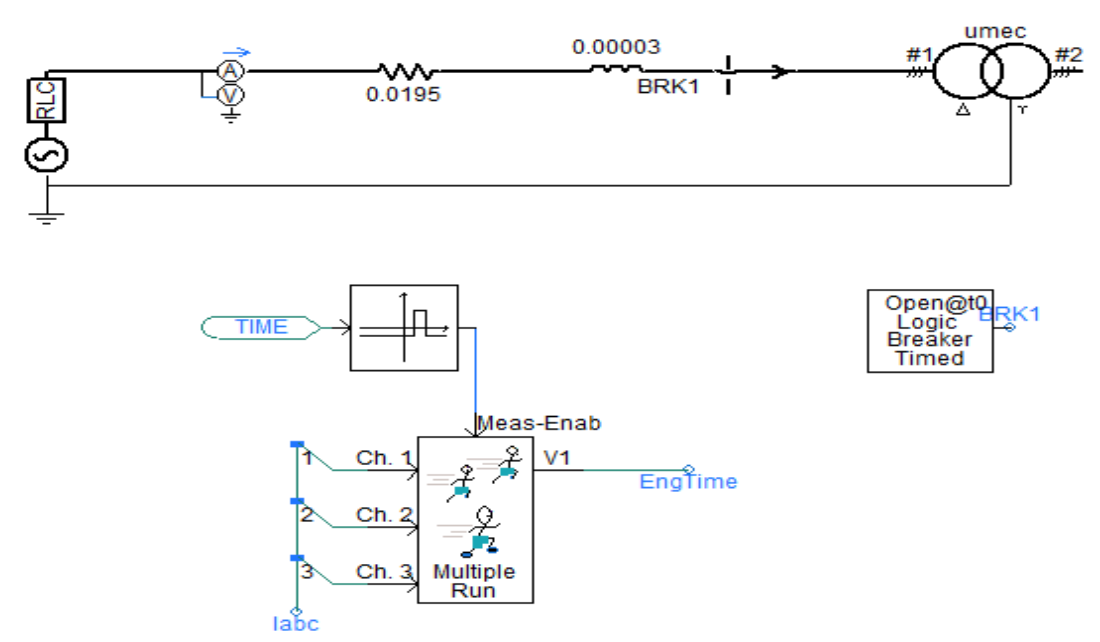

Figure 1: PSCAD Test Model 


\section{INITIAL STUDIES}

The aim of this initial Study is to predict the dynamic effects of the energisation of the 10MVA $132 / 11 \mathrm{kV}$ transformer (T1). The following tests are carried out and the inrush currents (in $\mathrm{kA}$ ) and voltages (in $\mathrm{kV}$ ) measured at the point of connection to the DNO network for the simultaneous energisation of the unloaded transformer. The voltage dips are calculated from the steady-state voltage before the event.

The latter part of the above figure represents the configuration of the PSCAD's multiple-run component used for the simulations.

\subsection{Case 1 - Normal System Impedance (50MVA)}

As shown in Section 2.1, the minimum three-phase fault level for the $11 \mathrm{kV}$ DNO network is 50 MVA; this allows for the worst case voltage dip. Figure 2 shows that the inrush current has a peak value of $0.741 \mathrm{kA}$ (i.e. $741 \mathrm{~A}$ ) as soon as $\mathrm{T} 1$ is energised at 1 sec. For the existing 1MVA $11 \mathrm{kV}$ site supply results in a rated current of 52.5A. The magnitude of the inrush current associated with this unloaded 10MVA $132 \mathrm{kV} / 11 \mathrm{kV}$ transformer is significant enough to trip protection at the $11 \mathrm{kV}$ supply. Figure 3 illustrates a dip in the POC $11 \mathrm{kV}$ RMS voltage to $10.68 \mathrm{kV}$ i.e. $0.97 \mathrm{pu}$ (a dip of $3 \%$ ) with the energisation of T1 after $1 \mathrm{sec}$.

\subsection{Case 2 - Variation in System Fault Impedance}

We are assuming that the $\mathrm{X} / \mathrm{R}$ at the $\mathrm{POC}$ remains as 0.50 , then the equivalent source parameters for various three-phase fault levels are shown in Table 1. The summary of the results for above source impedances are shown in Table 2. For an extreme case, with infinite MVA at the $11 \mathrm{kV}$ POC, Figure 4 shows that the inrush current has a peak value of $1.81 \mathrm{kA}$ and Figure 5 shows the RMS voltage of $1 \mathrm{pu}$ at the $11 \mathrm{kV}$ POC.

Table 1: Source Impedance Values for various Fault Levels

\begin{tabular}{ccccc}
\hline $\begin{array}{c}\text { 3-phase Fault } \\
\text { Impedance } \\
\text { (MVA) }\end{array}$ & $\mathrm{Z}(\Omega)$ & $\mathrm{R}(\Omega)$ & $\mathrm{X}(\Omega)$ & $\mathrm{L}$ (in H) \\
100 & 1.21 & 1.08 & 0.541 & 0.00173 \\
150 & 0.807 & 0.72 & 0.361 & 0.0015 \\
200 & 0.605 & 0.54 & 0.270 & 0.00087 \\
250 & 0.484 & 0.432 & 0.216 & 0.00069 \\
$\infty$ & & 0 & & \\
\hline
\end{tabular}

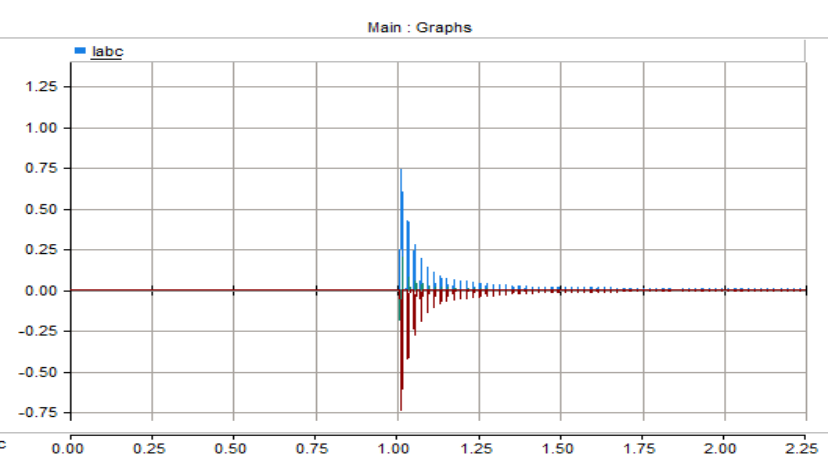

Figure 2: Inrush currents following the energisation of T1

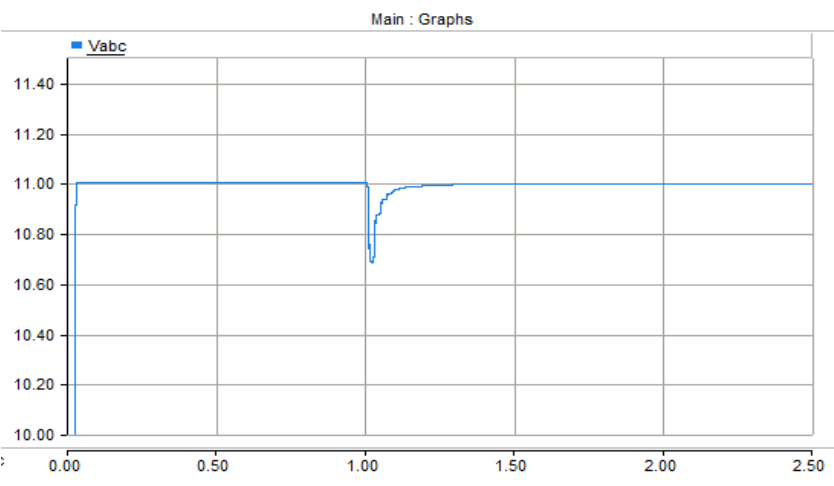

Figure 3 - RMS Voltage profile following the energisation of $T 1$

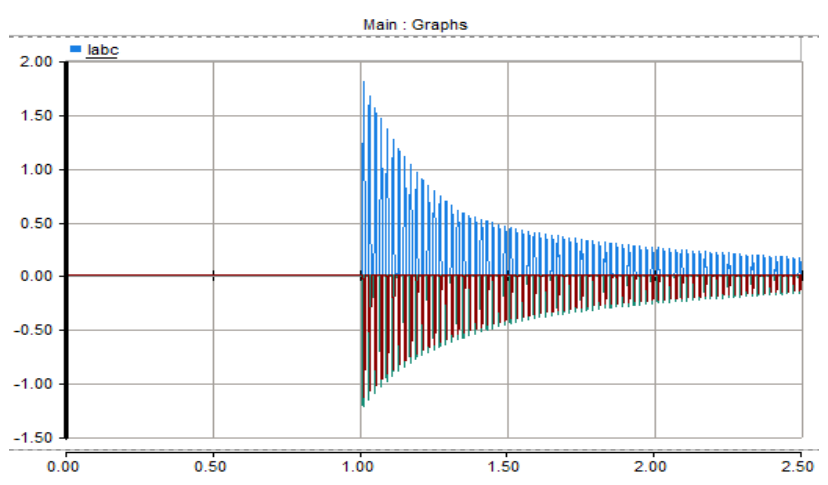

Figure 4: Inrush currents following the energisation of T1 (for $\infty$ MVA)

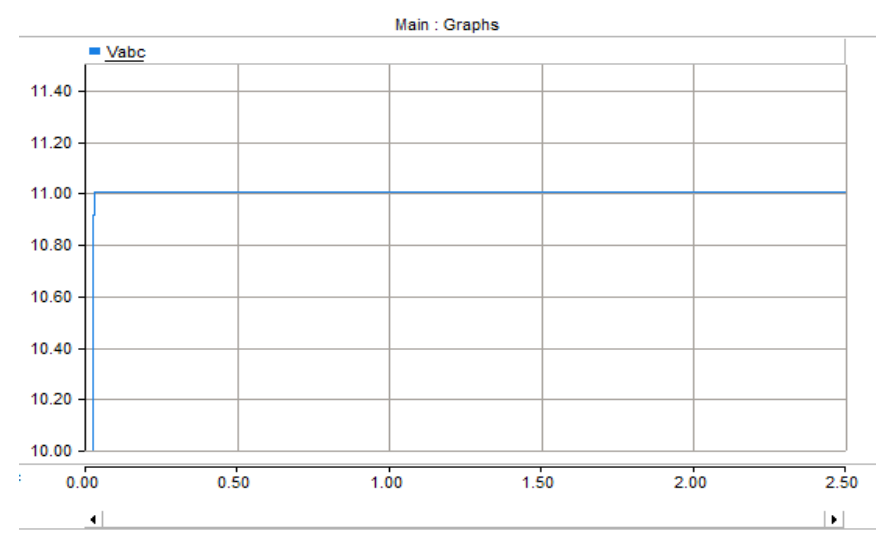

Figure 5: RMS Voltage profile following the energisation of 1 ( for $\infty M V A$ ) 
Table 2: Summary of Inrush Currents and Voltage Dips

\begin{tabular}{|c|c|c|c|c|}
\hline \multirow{3}{*}{ Case Study } & \multicolumn{4}{|c|}{ Energisation of T1 } \\
\hline & \multirow{2}{*}{ Inrush Current (kA) } & \multicolumn{3}{|c|}{ Voltage } \\
\hline & & $(\mathrm{kV})$ & $(\mathrm{pu})$ & $\%$ dip \\
\hline System Normal - 50MVA Fault level & 0.741 & 10.68 & 0.97 & 3 \\
\hline 100MVA Fault level & 0.994 & 10.80 & 0.982 & 1.8 \\
\hline 150MVA Fault level & 1.134 & 10.82 & 0.984 & 1.6 \\
\hline 200MVA Fault level & 1.22 & 10.84 & 0.985 & 1.5 \\
\hline 250MVA Fault level & 1.27 & 10.86 & 0.987 & 1.3 \\
\hline$\infty$ MVA Fault level & 1.81 & 11 & 1.0 & 0 \\
\hline
\end{tabular}

The results in Table 2 show that:

- The inrush currents could be as much as $0.741 \mathrm{kA}$ resulting in a voltage dip of $3.0 \%$ on the $11 \mathrm{kV}$ POC during normal system operation with 50MVA minimum fault level.

- $\quad$ The voltage dip will decrease with increasing fault levels. At the 250MVA fault level, the voltage dip could be as low as $1.3 \%$ on the $11 \mathrm{kV}$ POC; this drops to zero, if an infinite fault level is assumed at the POC (i.e. $\mathrm{R}=0$ ).

\section{MITIGATION MEASURES}

The estimation of the transformer inrush currents was carried out in the last Section to confirm that there will be an issue with the $11 \mathrm{kV}$ incoming supply. This Section will discuss the mitigation measures that may be used to minimise the impact of transformer energisation. Such measures, as reported in the literature, include:

- $\quad$ pre-insertion of resistors in $11 \mathrm{kV}$ circuit breaker [13]

- $\quad$ tap changing of the transformer [14]

- $\quad$ voltage stepping/gradual voltage increase [15]

- use of bank of resistors

- $\quad$ point-on-wave controlled switching [16]

The above practical measures are considered in turn:

\subsection{Use of a pre-insertion of resistors in $11 \mathrm{kV}$ circuit breaker}

The principle here is that when a transformer draws a large inrush current, the corresponding voltage drop across the pre-insertion resistor assists in reducing the voltage applied across the transformer thus the transformer flux. This will reduce the inrush current. A higher value of resistance reduces the inrush current and ensures that the voltage depression is limited to lower levels. But this option is discounted because the:

- $\quad I^{2} \mathrm{R}$ losses through the resistor would be very high and it may not be possible to actually get a resistor that can cope with this.
- resistor would have to be included with the circuit breaker design. In fact, the circuit breakers equipped with pre-insertor resistors are no longer available off the shelf for voltages less than $500 \mathrm{kV}$ [9].

- time of resistance insertion along with the time at which it is by-passed are the parameters that influence the effectiveness of this option.

\subsection{Use of a tap changing of the transformer}

The basis is to investigate the possibilities of reducing the inrush current by selecting the highest tap for the 10MVA $132 / 11 \mathrm{kV}$ transformer in order to reduce the core flux levels and thus reduce the effects of saturation [14]. This ensures that a much higher number of turns is excited. Though this option is considered to be very cheap as no additional costs are incurred, it is not a suitable option as the 10MVA $132 / 11 \mathrm{kV}$ transformer has a tapping limit of $\pm 5 \%$ but is not equipped with an on-load tap changer (OLTC) facility.

\subsection{Voltage stepping/gradual voltage increase}

The objective here is to investigate the possibilities of energising the 10MVA $132 / 11 \mathrm{kV}$ transformer directly from an $11 \mathrm{kV} 1 \mathrm{MVA}$ power source. If this transformer is initially connected to a source of 0 volts, then the voltage of the source (together with the transformers) is increased from 0 to nominal. The voltage of the source should be raised in a linear manner over a few seconds. The gradual increase of the applied voltage shrinks the non-linear magnetic saturation characteristics (i.e. the B-H curve) of the transformers and ultimately avoids inrush currents [15]. This approach is discounted because:

- $\quad$ as before, the 10MVA $132 / 11 \mathrm{kV}$ transformer is not equipped with on-load tap changers facility.

- there may be other protection and control issues problems hence many more engineering issues to be resolved. 


\subsection{Use of a bank of resistors}

The resistance on the $11 \mathrm{kV}$ side of the $132 / 11 \mathrm{kV}$ transformer is varied from $20 \Omega$ to $120 \Omega$ and the results are shown in Table 3. A higher value of resistance reduces both the inrush current and voltage dip.

Table 3: Effect of variable resistor on Inrush Currents and Voltage Dips

\begin{tabular}{ccccc}
\hline & \multicolumn{4}{c}{ Energisation of T1 } \\
\cline { 2 - 5 } Resistance & Inrush & \multicolumn{3}{c}{ Voltage } \\
\cline { 3 - 5 }$(\Omega)$ & $\begin{array}{c}\text { Currents } \\
(\mathrm{A})\end{array}$ & $(\mathrm{kV})$ & $(\mathrm{pu})$ & $\%$ dip \\
\hline 20 & 229 & 10.86 & 0.987 & 1.3 \\
40 & 136 & 10.92 & 0.993 & 0.7 \\
60 & 96 & 10.94 & 0.995 & 0.5 \\
80 & 74 & 10.96 & 0.996 & 0.4 \\
100 & 60.6 & 10.98 & 0.998 & 0.2 \\
120 & 52 & 10.99 & 0.999 & 0.1 \\
\hline
\end{tabular}

The simulations show that a resistance of $120 \Omega$ on the $11 \mathrm{kV}$ side of the $132 / 11 \mathrm{kV}$ transformer reduced the inrush current from $0.741 \mathrm{kA}$ (i.e. $741 \mathrm{~A}$ ) to about $52 \mathrm{~A}$ (just below the rated current (52.5A) of a 1MVA power supply at $11 \mathrm{kV}$ ) with the RMS voltage of $10.99 \mathrm{kV}$ (i.e. 0.999 pu and a dip of $0.1 \%$ ).

\subsection{Use of a point-on-wave (POW) controlled switching} This method uses synchronised switching but requires independent-pole operated circuit breakers and knowledge of residual fluxes to achieve optimal energisation. If no POW controller is applied, the energisation of the transformer may occur at any time on the sinusoidal wave resulting in high inrush currents particularly if the transformer core is moved into saturation [16]. It is generally observed that POW would not entirely eliminate inrush currents because of the effects of residual flux. The authors note that there are equipment vendors who offer a POW switching solution that reduces the effects of residual flux. The authors made contacts with two manufacturers offering solutions to limit possible transformer inrush currents but did not receive further details. In the absence of such information, this option was not further investigated.

\section{CONCLUSIONS}

This paper has presented a PSCAD study to model the energisation of the 10MVA $132 / 11 \mathrm{kV}$ transformer. The aim was to provide the basic inrush characteristics and system response in terms of voltage dips as well as propose mitigation measures to minimise the impact of transformer energisation.

These studies required high level Electromagnetic Transients (EMT) models. These models were developed in the EMT program PSCAD which is a time domain based simulation package hence suitable for the analysis of switching transients. As a result of these investigations, the following conclusions are reached:

- The inrush currents could be as much as $0.741 \mathrm{kA}$ resulting in a voltage dip of $3 \%$ on the $11 \mathrm{kV}$ POC during normal system operation with 50MVA minimum fault level.

- $\quad$ The voltage dip will decrease with increasing fault levels. At the extreme (with a 250MVA fault level at the $11 \mathrm{kV}$ POC), the voltage dip could be as low as $1.3 \%$ on the $11 \mathrm{kV}$ POC and $0 \%$ at the theoretical infinite bus case.

- Under the normal system impedance of 50MVA (minimum fault level which represents the worst case for the voltage dip), a preferred solution to the problem of transformer inrush currents is to use of about $120 \Omega$ resistor on the $11 \mathrm{kV}$ side of the $132 / 11 \mathrm{kV}$ transformer. The resistance of $2.16 \Omega$ used in Section 2.1 represented the $11 \mathrm{kV}$ network source impedance of the DNO network. The $120 \Omega$ resistor limits the inrush current to the $132 / 11 \mathrm{kV}$ transformer.

\section{ACKNOWLEDGEMENTS}

A. O. Ekwue is grateful to his colleagues Messrs $\mathrm{R}$ Fairbairn and K Frearson for useful discussions held on the subject of this paper. The views expressed in this paper are those of the authors and do not represent those of Jacobs Engineering Inc. or Brunel University London.

\section{REFERENCES}

[1] ER P28, "Planning limits for voltage fluctuations caused by industrial, commercial and domestic equipment in the United Kingdom", Issue 1, 1989.

[2] Hase Y, Kamesawa T, Inoue S and Yamamura S, "Experimental Study of Transformer Residual Flux and the Method of Restraining Inrush Current", Electrical Engineering in Japan, vol. 188, no. 4, pp $54-67,2014$.

[3] Ge W, Wang Y, Zhao Z, Yiang X and Li Y, "Residual Flux in the Closed Magnetic Core of a Power Transformer", IEEE Transactions on Applied Superconductivity, vol. 24, no.3 June 2014.

[4] Chiesa N, "Power Transformer Modelling for Inrush Current Calculation", PhD thesis submitted to Norwegian University of Science \& Technology, Trodheim, June pp 226, 2010.

[5] Purohit T. P. and Bhavsar P. K, "Sympathetic Inrush phenomena in parallel and series connected transformers using PSCAD", Third International Conference on Emerging 
Technologies in Engineering, Biomedical, Management and Science, 9 July, pp 125-130, 2017.

[6] Peng J, "Assessment of Transformer Energisation Transients and their impacts on Power Systems", PhD thesis submitted to the University of Manchester, pp 1 - 225, 2013.

[7] Yacamini $\mathrm{R}$ and Abu-Nasser A, "Numerical calculation of inrush current in single-phase transformers" IEE Proceedings - Electrical Power Applications, vol. 128, no. 6, pp 327 - 334, 1981.

[8] Yacamini R and Abu-Nasser A, "The calculation of inrush current in three-phase transformers, "IEE Proceedings B, Electrical Power Applications, vol. 133, no. 1, pp $31-40,1986$.

[9] "Transformer Energization in Power Systems: A Study Guide", CIGRE Working Group C4.307, Technical Brochure No: 568, February, pp 1 - 126, 2014.

[10] Chiesa N, Hoidalen H K, Lambert M and Duro M M, "Calculation of Inrush Currents - Benchmarking of Models", International Conference on Power Systems Transients held in Delft, The Netherlands, June 14-17 2011

[11] Chiesa N and Hoidalen H. K., "Analytical algorithm for the calculation of magnetisation and loss curves of delta-connected transformers", IEEE Transactions on Power Delivery, vol. 25, no. 3, July, pp 1620 - 1628, 2010.
[12] Chiesa N, Mork B. A. and Hoidalen H. K., "Transformer model for inrush current calculations: simulations, measurements and sensitivity analysis", IEEE Transactions on Power Delivery, vol. 25, no. 4, October, pp 2599 - 2608, 2010.

[13] Hu J, Bisewski B, Maki D and Marz M B, "Mitigation of Voltage Drop Using Pre-Insertion Resistor during Large Transformer Energisation in a Weak System: Simulation and Field Verification", International Conference on Power System transients (IPST2011) in Delft, The Netherlands, June 14-17 2011.

[14] Bronzeado H. S. and de Oliveira J. C, "The Influence of Tap Position on the Magnitude of Transformer Inrush Current", International Conference on Power System Transients (IPST1999) in Budapest, Hungary, 20 - 24 June, pp 457 - 461, 1999

[15] Ansen C P J, Slootweg J G and de Groot R A C T, "Calculation of transformer inrush currents occurring during the energising of the public grid after a major black out", Proceedings of the Power Tech, 2005 IEEE Russia, St Petersburg, 27 - 30 June 2005.

[16] Prikler L, Banfai G, Ban G and Becker P, "Reducing the magnetising inrush current by means of controlled energisation and de-energisation of large transformers", Electrical Power Systems Research Journal, vol. 76, pp 642-649, 2006. 